\title{
Management of hypoactive sexual desire disorder in women: current and emerging therapies
}

This article was published in the following Dove Press journal:

International Journal of Women's Health

29 June 2010

Number of times this article has been viewed

\author{
Rossella E Nappi ${ }^{1,2}$ \\ Ellis Martini ${ }^{1,2}$ \\ Erica Terreno ${ }^{1,2}$ \\ Francesca Albani \\ Valentina Santamaria ${ }^{1,2}$ \\ Silvia Tonani MD ${ }^{1,2}$ \\ Luca Chiovato MD² \\ Franco Polatti MD' \\ 'Research Center for Reproductive \\ Medicine, Section of Obstetrics \\ and Gynecology, Department of \\ Morphological, Eidological and \\ Clinical Sciences, ${ }^{2}$ Gynecological \\ Endocrinology and Menopause Unit, \\ Department of Internal Medicine \\ and Endocrinology, IRCCS Maugeri \\ Foundation; University of Pavia, Italy
}

Correspondence: Rossella E Nappi IRCCS Fondazione "S Maugeri",Via Ferrata 8, 27100 Pavia, Italy

Email renappi@tin.it

\begin{abstract}
Hypoactive sexual desire disorder (HSDD) is a common multifactorial condition which is characterized by a decrease in sexual desire that causes marked personal distress and/ or interpersonal difficulty. The general idea that HSDD is a sexual dysfunction difficult to treat is due to the large number of potential causes and contributing factors. Indeed, a balanced approach comprising both biological and psycho-relational factors is mandatory for accurate diagnosis and tailored management in clinical practice. There are currently no approved pharmacological treatments for premenopausal women with HSDD, while transdermal testosterone is approved in Europe for postmenopausal women who experience HSDD as a result of a bilateral oophorectomy. Even though the role of sex hormones in modulating the sexual response during the entire reproductive life span of women is crucial, a better understanding of the neurobiological basis of sexual desire supports the idea that selective psychoactive agents may be proposed as nonhormonal treatments to restore the balance between excitatory and inhibitory stimuli leading to a normal sexual response cycle. We conclude that the ideal clinical approach to HSDD remains to be established in term of efficacy and safety, and further research is needed to develop specific hormonal and nonhormonal pharmacotherapies for individualized care in women.
\end{abstract}

Keywords: sexual desire, distress, testosterone, psychoactive drugs, psychosexual interventions

\section{What is hypoactive sexual desire disorder?}

Low sexual desire is a very common symptom in women of any age with potential negative consequences on quality of life and well-being. ${ }^{1-3}$ The American Psychiatric Association's Diagnostic and Statistical Manual of Mental Disorders (DSM-IV TR $)^{4}$ and the World Health Organization's International Classifications of Disease-10 (ICD-10 $)^{5}$ established that the definition of hypoactive sexual desire disorder (HSDD) should include not only the lack or absence of sexual fantasies or desire for any form of sexual activity, but also the presence of personal distress and/or interpersonal difficulties. Generalized acquired HSDD is the most common diagnosis when the condition is not dependent on a specific situation or relationship and has developed after a period in which sexual desire and sexual functioning were considered normal. A diagnosis of HSDD may be comorbid with another sexual dysfunction, but it cannot be exclusively attributed to another medical condition or to the physiological effects of a medication. ${ }^{6,7}$ The very recent recommendations from the 3rd International Consultation on Sexual Medicine (ICSM) ${ }^{8,9}$ pointed out that the definition of HSDD needs a revision because there is a great heterogeneity among women in the sexual response models they identify 
with, ${ }^{10}$ and new criteria have been proposed for consideration in the forthcoming DSM-V. ${ }^{11}$

Key findings from large population-based studies (the Prevalence of Female Sexual Problems Associated with Distress and Determinants of Treatment Seeking [PRESIDE] and the Women's International Study of Health and Sexuality [WISHeS]) analyzing the prevalence of sexual symptoms associated with distress across the United States (US) and Europe, clearly indicate that female sexual dysfunction (FSD) is a real burden for many women and approximately one in ten women may receive a diagnosis of HSDD. ${ }^{3}$ The PRESIDE study was conducted with more than 31,000 women aged over 18 years in the US and documented that the prevalence of sexual distress symptoms, including HSDD which was the most commonly reported, peaked in middle-aged women. Between 18 and 44 years of age the prevalence of HSDD was $8.9 \%$, while it was $12.3 \%$ between $45-64$ years and $7.4 \%$ in women 65 years old or older. In addition, the odds of distressing desire problems increased with worsening of self-assessed health and were approximately $20 \%$ higher in postmenopausal than in premenopausal women. ${ }^{3}$ WISHeS involved over 3,500 women between 20-70 years of age, resident in the US and in four Western European countries. The prevalence of HSDD ranged from $6 \%-13 \%$ in Europe and $12 \%-19 \%$ in the US, and the proportion of women with low desire associated with distress was significantly higher in younger women in comparison with older women. ${ }^{12,13}$ Surgically menopausal women were significantly more likely to experience HSDD than their age-matched counterparts who did not have surgery, and a younger age was a risk factor for being emotionally and psychologically distressed by low desire, with a less active sex life and decreased sexual and relationship satisfaction. ${ }^{14}$ The negative personal issues associated with decreased sexual interest include feeling less feminine, feeling like a sexual failure, low self-esteem, insecurity, inadequacy and letting partner down. ${ }^{12,13}$ Moreover, a higher percentage of women with low sexual desire feel frustrated, concerned, unhappy, disappointed, hopeless, troubled, ashamed, and bitter, compared with women with normal desire. ${ }^{12,13}$ Finally, the distress is positively associated with depression ${ }^{15}$ and it is particularly evident when a current partner is present. ${ }^{16}$ Women who are better able to communicate their sexual needs report less distress associated with low sexual function. ${ }^{15}$

That being so, it is a duty of health care providers to address the issue of sexuality routinely in clinical practice and to recognize the distress eventually associated with sexual dysfunction. However, it is still quite difficult to engage in sexual conversation because of many barriers and misconceptions, including the idea that sexual problems are a normal part of aging, menopause, long relationship, etc, and do not deserve specific treatments. ${ }^{17,18}$ In addition, the multitude of determinants of sexual desire across the life cycle and the difficulties in establishing the level of discrepancy between expected and current desire in a specific relational context bring about the idea that HSDD is a condition difficult to treat. On the other hand, personal experiences and cultural norms may modulate the clinical relevance of sexual symptoms and the level of response to specific treatments. ${ }^{19}$

Here we attempt to summarize the most common therapeutic strategies available to help women with HSDD in a balanced perspective by integrating basic counseling and medical and/or psychosocial interventions, as appropriate. By no means is it either a systematic review or a meta-analysis of all the available evidence in this complex field, and it merely reflects the opinion of the authors on addressing the various facets of HSDD in clinical practice.

\section{Contributors to HSDD}

An accurate diagnosis of HSDD is crucial to understand the potential causes and, eventually, to establish treatment strategies with drugs. ${ }^{20}$ On the other hand, being aware of the complexity of contributors driving the healthy sexual response cycle, intrapersonal and interpersonal factors need to be addressed and adequately treated with tailored counseling and psychosexual approaches. ${ }^{21}$

A recent conceptualization of HSDD implies that such sexual dysfunction may be the result of the inability of the neuroendocrine circuitries to integrate the complex nature of sexual response encompassing physiological, psychological, emotional, and/or relationship components. ${ }^{22-24}$ Current research suggests that neurotransmitters, strongly influenced by sex hormones (estrogen, androgens, and even progesterone), play a key role in modulating sexual desire. When an imbalance between the dopaminergic system (which increases sexual desire and excitement) and norepinephrine system (which affects arousal and orgasm) occurs, women may feel unable to begin the sexual response cycle. In addition, an overactive serotoninergic system can decrease desire and delay orgasm. The net balance between stimulating and inhibitory factors brings about the ability to experience sexual desire and eventually to engage in sexual activity. Other mediators have been postulated to play a critical role in women's sexuality, including oxytocin, melanocortins, opioid, and endocannabinoid systems. Sexual excitation can be primed internally by sex hormone actions or externally 
by sexual incentives or substances that activate excitatory neurochemical systems. However, when endogenous inhibitory mechanisms are tonically activated by situational variables, such as stress and fatigue, and/or by compounds that reinforce inhibition (ie, selective serotonin reuptake inhibitors [SSRIs]) or, alternatively, sexual excitatory mechanisms are endogenously blunted, as it may occur in some hormonal and/or metabolic conditions, several amounts of FSD may be present and sexual symptoms may be co-occurring in the same woman. ${ }^{25}$ Therefore, even though psychorelational issues and sociocultural factors should always be ruled out, there is no doubt that biological aspects, including sex hormone deficiency, as well as other medical conditions and medications which may cause a neuroendocrine imbalance, play a major role in the clinical manifestation of sexual problems that induce personal distress and, therefore, may require intervention. ${ }^{26,27}$ Indeed, the iatrogenic removal of both ovaries, which may occur well before the age of natural menopause, is characterized by the effects of acute estrogen and even androgen deprivation in several domains of sexual function (desire, arousal, lubrication, orgasm, satisfaction) and has been significantly associated with HSDD and severity of other menopausal symptoms such as vaginal dryness. ${ }^{28-30}$ Following bilateral oophorectomy, both premenopausally and postmenopausally, there is a sudden $50 \%$ fall in circulating testosterone ( $\mathrm{T}$ ) levels which have been associated with the so-called androgen-insufficiency syndrome; an increasingly accepted clinical entity comprising specific symptoms such as low sexual desire, persistent and inexplicable fatigue, blunted motivation and a general reduced sense of wellbeing. ${ }^{31}$ It is also known that $\mathrm{T}$ significantly declines with age, independently from the menopausal transition, because of a progressive reduction of adrenal production. Menopausal women have decreased androgens compared to younger women but the aging ovary is still capable of producing a variable amount of androgens with relevant effects on women's general and sexual health depending on the bioavailability of sexual hormones within target tissues..$^{32,33} \mathrm{On}$ the other hand, a major source of sex hormones in women after menopause is the inactive precursor steroid dehydroepiandrosterone (DHEA) of adrenal origin, which is converted into active androgens and/or estrogens in specific peripheral tissues. ${ }^{34}$ That being so, data collected in a community-based, cross-sectional study of 1423 Australian women (age range: 18-75 years) failed to demonstrate a correlation between plasma $\mathrm{T}$ levels ${ }^{35}$ and sexual symptoms. In addition, no cut-off level for a normal range of $\mathrm{T}$ has been agreed on and the lack of consensus on the definition of low $\mathrm{T}$ levels depends namely on the difficulties with sensitive assays of total and free $\mathrm{T}$ in women. ${ }^{32}$ In the same Australian study sample, an association between plasma dehydroepiandrosterone sulphate (DHEAS) levels below the 10th percentile and low scores on several sexual function domains was found.$^{34}$ However, the majority of women with low DHEAS levels did not report low sexual function, confirming other findings reporting a wide range of androgen circulating levels in fertile women with normal sexual function. ${ }^{36}$

Even women with natural menopause report a high rate of FSD with a variable prevalence across studies depending on several factors (ie, sample, design, menopausal symptoms, sociocultural background, etc). ${ }^{37}$ The longest duration population-based study, the Melbourne Women's Midlife Health Project, found a significant decrease of women's desire, arousal, orgasm, and frequency of sexual activity, and a significant increase in vaginal dryness/dyspareunia, with a rate of sexual dysfunction that ranged from $42 \%$ to $88 \%$ throughout the menopausal transition. ${ }^{38,39}$ However, only $17 \%$ of women were sexually distressed, supporting the notion that sexual symptoms are quite normal at menopause and they are clinically relevant only when exerting a significant impact on intrapersonal and interpersonal wellbeing. ${ }^{40}$ Indeed, both age and declining estradiol $\left(\mathrm{E}_{2}\right)$ levels had significant detrimental effects on sexual functioning, desire, and sexual responsiveness (arousal, sexual pleasure, and orgasm). Interestingly enough, by investigating the relative effects of hormonal and relationship factors in sexual function during the natural menopausal transition, it has been demonstrated that the best predictors of sexual function were prior level of sexual function, change in partner status, feelings for partner, and $\mathrm{E}_{2}$ level $(\mathrm{R} 2=0.65)$. Moreover, the minimum effective dose of $\mathrm{E}_{2}$ needed to increase sexual response by $10 \%(700 \mathrm{pmol} / \mathrm{L}=190.7 \mathrm{pg} / \mathrm{mL})$ is twice that needed to decrease dyspareunia, supporting the notion that other hormonal-mediated mechanisms, modulating physical and mental well-being more broadly, are significantly involved in sexual functioning across the menopause. ${ }^{41} \mathrm{To}$ further reinforce the idea that HSDD is a multidimensional condition, a cross-sectional study conducted in a sample of US and European women between 18 and 65 years of age reported that women suffering from characteristics of HSDD have more negative patterns of partner interactions. ${ }^{42}$ Finally, the PRESIDE study identified current depression, anxiety, thyroid problems, and urinary incontinence as the medical conditions positively associated with HSDD, but many other chronic diseases and related treatments may be significantly associated with distressing low sexual desire, including 
the use of antihormones, chemotherapies and recreational substances. ${ }^{3}$

From a practical point of view, the diagnosis of HSDD should encompass the major biological causes such as states of sex hormone deficiency, especially low androgens, mood disorders, including anxiety and depression, and many clinical conditions and related medications with a potential impact on women's sexual function. On the other hand, intrapersonal and interpersonal issues, including partner's general/sexual health and duration/quality of the relationship, and sociocultural aspects in the context of the life cycle stage should be taken into account for a comprehensive approach.

That notwithstanding, the possibilities of treating HSDD are multifaceted and should include the combination of pharmacological treatments able to maximize biological signals driving the sexual response, and individualized psychosocial therapies in order to overcome personal and relational difficulties. ${ }^{43,44}$

\section{Current treatments for HSDD}

The complexity of factors involved in HSDD and the poor awareness that low desire associated with distress is a medical condition, have slowed down the development of drugs specifically designed for women with FSD. The investigation on FSD is, indeed, a rapidly evolving area in which definitions and models for women's sexual functioning are being continually reviewed and revised. ${ }^{7}$ A large amount of literature has been devoted to the role of sex hormones, especially androgens, in the treatment of HSDD in postmenopausal women. ${ }^{45,46}$ However, a better understanding of physiology and pathophysiology, together with the recognition of the most appropriate inclusion and exclusion criteria for FSD trials and the development of sensitive diagnostic instruments to identify the main outcome measures suitable for the evaluation of drug interventions, have stimulated progression in this area of research both in premenopausal and postmenopausal women. ${ }^{19,26,47}$

The impact of endocrine factors in women's sexual function have been recently revised ${ }^{48}$ and, even though the distinct effects of estrogens and androgens on sexual desire, arousal, and receptivity are still not completely understood, it is clear that the endocrine milieu plays a critical role in setting the threshold to sexual stimuli at least in some individuals. ${ }^{45,46}$

Hormone therapy (HT) with estrogen alone (ET), as it is indicated in hysterectomized menopausal women, and with estrogen-progestin (EPT), as it is currently used in menopausal women with intact uterus, has been the first-line hormonal treatment for women reporting menopausal symptoms (mainly hot flushes) across menopausal transition and beyond. In addition, systemic ET/EPT, and even local ET, may be an effective treatment for vulvovaginal atrophy with a potential positive effect on sexual function due to the improvement of lubrication. However, in spite of the reduction of dyspareunia, some women with FSD remain unresponsive because ET/EPT does not consistently increase sexual desire or activity, especially in surgical menopause. ${ }^{49,50}$ Indeed, the first randomized clinical trial suggesting that sexual desire problems respond better to androgen therapy (AT), and even better to combined AT/ET, rather than to ET alone, was conducted by Greenblatt et al in 1950 in a sample of ovariectomized women. ${ }^{51}$ Since then, several studies have been conducted demonstrating that androgens may play a role in enhancing sexual desire and arousal in women, but these early findings were often related to supraphysiological doses of testosterone. ${ }^{46}$ Two Cochrane reviews have recently examined the benefits and risks of T plus EPT versus EPT alone for peri- and postmenopausal women by including 35 studies with 4,768 participants. ${ }^{52,53}$ The majority of the trials with several $\mathrm{T}$ regimens (oral tablets, intramuscular injections, subcutaneous implants, transdermal patches/ gels) included only postmenopausal women, both naturally and surgically menopausal. The median study duration was 6 months (range 1.5-24 months) and many methodological limitations were outlined. However, the pooled estimate from the clinical trials suggested that the addition of T to HT regimens improved sexual function scores and number of total satisfying sexual episodes in postmenopausal women. Beneficial effects were seen for the composite sexual function score and domains of sexual activity, coital frequency, responsiveness, and desire.

Adverse effects included increased incidence of excess hair growth and acne and decreases in high-density lipoprotein (HDL) cholesterol levels with oral T therapy, but not with transdermal $\mathrm{T}$ treatment which bypasses hepatic metabolism. Discontinuation from treatment was similar between groups. There was insufficient evidence of a treatment effect for perimenopausal/premenopausal women or for other outcomes examined, including well-being, fatigue, menopausal symptoms, cognition, body composition, and bone health. Another large review of safety data also concluded that, except for hirsutism and acne, the therapeutic administration of $\mathrm{T}$ in physiologic doses was safe for up to several years. ${ }^{54}$

A series of double-blind, randomized, placebo-controlled studies examined the efficacy and safety of a transdermal T patch $(300 \mu \mathrm{g})$ in postmenopausal women with HSDD. ${ }^{55,56}$ 
Two multicenter trials evaluated 24 weeks of $\mathrm{T}$ patch treatment in over 1,000 surgically menopausal women with HSDD receiving concomitant estrogen therapy. At baseline, women reported approximately three satisfying sexual episodes in 4 weeks, with a mean increase of approximately two events in T-treated women, compared with an increase of one satisfying event with placebo. A $450 \mu \mathrm{g}$ patch, however, did not confer benefit beyond placebo suggesting the lack of a dose response effect of the T patch. ${ }^{57}$ In addition to increased sexual activity, significant improvements were seen in all domains of sexual function in T-treated women compared with placebo, including desire, arousal, orgasm, pleasure, concerns, responsiveness, sexual self-image, and distress. Despite the low absolute change in satisfying sexual events, the degree of benefit seen with $\mathrm{T}$ therapy in these studies was "clinically meaningful" to women. ${ }^{58}$ Adverse event profiles were similar except for a higher incidence of unwanted hair growth in T-treated women. Other androgenic adverse events such as acne, alopecia or voice deepening were more common in T-treated women, though not statistically significant. The safety and efficacy of transdermal $\mathrm{T}(300 \mu \mathrm{g})$ for 24 weeks was also studied in a double-blind, placebo-controlled, randomized trial of 549 naturally menopausal women with HSDD on concomitant ET. Total satisfying sexual episodes increased significantly from baseline in T-treated women compared with placebo (2.1 episodes vs 0.5$).{ }^{59}$ Small but statistically significant improvements were also seen in all domains of sexual function assessed, including sexual desire and personal distress. As almost all studies of $\mathrm{T}$ therapy were performed in the setting of concurrent estrogen administration, a doubleblind, placebo-controlled trial examined the safety and efficacy of T treatment for HSDD in 814 postmenopausal women not receiving ET. ${ }^{60}$ Women were randomized to 150 or $300 \mu \mathrm{cg}$ of transdermal $\mathrm{T}$ per day or placebo; efficacy was measured to week 24 and safety to week 52 . The increase in the 4-week frequency of satisfying sexual episodes was significantly greater in the women receiving $300 \mu \mathrm{g}$ T per day compared with placebo (2.1 episodes vs. 0.7), although not in the group receiving the lower $\mathrm{T}$ dose (150 $\mu \mathrm{cg}$ per day). Both doses resulted in significant increases in desire and decreases in distress compared with placebo. Androgenic adverse events, principally unwanted hair growth, was higher in the women receiving $300 \mu \mathrm{cg}$ $\mathrm{T}$ compared with placebo, although rates of acne, alopecia and voice deepening were similar among the three groups. Vaginal bleeding was more common in the $300 \mu \mathrm{cg}$ T group, although no cases of endometrial hyperplasia or carcinoma were diagnosed. There were no differences between groups in vital signs or weight, serum lipid or lipoprotein profiles, measures of carbohydrate metabolism, liver function, or other laboratory tests. Breast cancer was diagnosed in four women who received $\mathrm{T}$, as compared with none who received placebo, but such evidence was not statistically meaningful. $T$ has been studied also in a small group of premenopausal women $(n=31$, age range: $30-45$ years $)$ with HSDD who were randomized to treatment with a $\mathrm{T}$ cream $(10 \mathrm{mg} / \mathrm{d})$ versus placebo in a double-blind crossover study for 12 weeks with a 4 week washout. T treatment resulted in statistically significant improvements in the composite scores and many subscale scores to measure sexual function and well-being. ${ }^{61}$

That being so, the European Medical Authority (EMEA) approved the transdermal $\mathrm{T}$ patch for surgically menopausal women with HSDD on concurrent ET, but $\mathrm{T}$ replacement therapy in women is still an ongoing debate. Indeed, in the US there is a combination of oral $\mathrm{E}+$ methyltestosterone (MT) approved for the treatment of moderate to severe vasomotor symptoms but no FDAapproved androgen treatments for HSDD. However, the increased off-label use of $\mathrm{T}^{62}$ supports the evidence that women are in need of medical therapies to relieve sexual dysfunction, and doctors feel positive about the safety and effectiveness of $\mathrm{T}$ formulations, at least on a short-term basis. ${ }^{63,64}$ Guidelines and position statements differ quite significantly, creating a therapeutic dilemma. ${ }^{65}$ In 2005, The North American Menopause Society concluded that postmenopausal women with decreased sexual desire associated with distress and with no other identifiable cause may be candidates for $\mathrm{T}$ therapy. ${ }^{66}$ Treatment is contraindicated in women with breast or uterine cancer, or in those with cardiovascular or liver disease. Women need to be informed of all potential risks and that data on long-term use are lacking, suggesting administration at the lowest dose for the shortest time. On the other hand, in 2006. The Endocrine Society concluded that although there is evidence for shortterm efficacy of $\mathrm{T}$ in selected populations, generalized use of testosterone by women is not recommended due to inadequate indications for treatment and the lack of evidence of safety in long-term studies ${ }^{67}$ Many commentaries have been written to critically discuss the topic, concluding that the decision to treat postmenopausal women with HSDD with $\mathrm{T}$ is mainly based on clinical judgment, after an informed consent regarding the unknown long-term risks of androgen treatment in women, namely cardiovascular diseases and breast cancer. ${ }^{48}$ 
Another potential option of HT for HSDD is tibolone, a synthetic steroid not available in the US, which is metabolized to two estrogenic metabolites, $3 \alpha$ and $\beta$, becoming active in target tissues. Tibolone itself and its $3 \beta$ metabolite is also converted to a $\Delta 4$-isomer which can activate both the progesterone and androgen receptor. Tibolone lowers sex hormone-binding globulin (SHBG) and increases circulating free testosterone, adding to its androgenicity. Apart from alleviating postmenopausal vasomotor symptoms and improving urogenital atrophy, some studies suggest that tibolone is effective in postmenopausal women with symptoms of sexual dysfunction. ${ }^{45,68}$ In a recent multicenter, double-blind, randomized, clinical trial, tibolone improved sexual wellbeing in postmenopausal women with low libido with improvements in desire arousal, satisfaction, and receptiveness, compared to those receiving transdermal estrogen-progestin therapy ${ }^{69}$ Even with tibolone some concerns have been raised about long-term use and risk of cardiovascular disease and/or breast cancer. ${ }^{48}$

There is conflicting evidence over the efficacy of DHEA (an androgen classed as a pro-hormone because it can be converted into a variety of biologically active androgens and estrogens) ${ }^{70}$ in improving sexual function, and at the present time the use of DHEA is not recommended in women with HSDD. $^{48}$

Plant-derived and herbal remedies are a very popular alternative to medical treatments, but the real effectiveness in improving sexual function in women is not proven. ${ }^{71}$ For example, Ginkgo biloba extract (GBE) which facilitates blood flow, influences nitric oxide systems, and has a relaxant effect on smooth muscle tissue, failed as an antidote to antidepressantinduced sexual dysfunction. ${ }^{72}$ The long-term effects of GBE on sexual function have been recently assessed in 68 sexually dysfunctional women who were randomly assigned to 8 weeks treatment of either (1) GBE (300 mg/daily), (2) placebo, (3) sex therapy which focused on training women to attend to genital sensations, or (4) sex therapy plus GBE. Interestingly enough, when combined with sex therapy, but not alone, longterm GBE treatment significantly increased sexual desire and contentment beyond placebo. ${ }^{73}$

To combine biomedical and psychosocial interventions is, indeed, the best approach to any kind of FSD to provide an optimal outcome. Basic sexual counseling should be always part of the consultation to provide information and to promote communication about sexual issues. ${ }^{74}$

As far as HSDD is concerned, individual or couplebased psychosexual therapy, with the additional counseling of the partner, may be proposed, even though most of the psychotherapy literature reported that HSDD is often treatment refractory. ${ }^{43}$ There is some evidence to support the efficacy of cognitive behavioral approaches in HSDD. ${ }^{75,76}$ However, the majority of psychosocial interventions have been conducted in premenopausal women and there is still a paucity of well-controlled studies in the field due to methodological problems in sex therapy outcome studies. ${ }^{77}$

\section{Emerging treatments in the management of HSDD}

The possibilities to treat HSDD are scarce, with transdermal $\mathrm{T}$ being the only approved treatment for postmenopausal women with FSD. Some authors with peculiar expertise in the field of FSD believe that the reason for the paucity of drugs under investigation is related more to the standards for clinical trials in women than to the potential efficacy of the drugs themselves. ${ }^{78}$ However, it is mandatory to develop new safe and effective hormonal and nonhormonal treatments of HSDD that can be approved by the health authorities both in pre- and postmenopausal women. We have mentioned before that research in laboratory animals and clinical observation in humans has suggested that acting on the balance of neurotransmitters, mainly increasing dopaminergic activity and decreasing serotoninergic activity, may have a prosexual effect. ${ }^{25}$ The picture is, of course, much more complicated that this simple statement and individual receptor subtypes, namely serotoninergic receptors $5 \mathrm{HT} 1 \mathrm{a}$ and 5 -HT2, have to be taken into account in order to explain different effects of specific drugs on sexual responsiveness. In addition, for most of the neuroactive compounds that have been investigated over time, mainly in premenopausal women, to avoid the potential impact of postmenopausal hormonal deficiency, there is a lack of well-controlled studies on the real efficacy and safety in clinical practice. ${ }^{43}$ That being so, it is worth mentioning here the mild to moderate prosexual effect of buproprion, a compound with both dopamine and norepinephrine reuptake inhibition, in some women with HSDD. ${ }^{79}$ Even apomorphine, a nonselective dopaminergic receptor agonist, has been postulated to be effective in premenopausal women affected by HSDD and arousal disorder. In a placebo-controlled pilot study including 62 volunteer women (26-45 years of age) daily apomorphine SL (2 or $3 \mathrm{mg}$ ) may improve the sexual life of women affected by sexual difficulties ${ }^{80}$ However, additional studies are needed to better establish the safety profile of the drug before recommending it in clinical practice.

On the basis of the long-term clinical experience with sexual side-effects of many antidepressants, flibanserin, 
a novel centrally acting compound with both 5HT2 antagonism and 5HT1a agonism ${ }^{81}$ is currently investigated to assess safety and efficacy in a large phase III clinical trial program (the Bouquet study program) involving over 5,000 premenopausal women with generalized acquired HSDD, recruited both in North America and Europe. In addition to binding to 5-HT1A and 5-HT2A receptors, flibanserin binds with moderate affinity to the dopamine D4 receptors. Preliminary data (Boheringer Inghelheim, data on file, 2009) have shown that flibanserin $100 \mathrm{mg}$ once-daily, taken at bedtime, is a well-tolerated potential treatment for HSDD in premenopausal women, while no data are presently available on the use of flibanserin in postmenopausal women.

In conclusion, the recognition that HSDD is a common condition that deserves not only cognitive behavioral therapy or other psychosocial approaches but also pharmacological treatments capable of increasing sexual desire and sexual function, while significantly decreasing the associated distress, represents a critical step in the field of FSD. Even though the ideal clinical approach to HSDD remains to be established, the use of androgen therapy represents a suitable option for postmenopausal women. Further research is needed to develop specific hormonal and nonhormonal pharmacotherapies for individualized care in women during the entire reproductive life cycle.

\section{Disclosure}

The authors report no conflicts of interest in this work.

\section{References}

1. Laumann EO, Paik A, Rosen RC. Sexual dysfunction in the United States: prevalence and predictors. JAMA. 1999;281(6):537-544.

2. Lindau ST, Schumm LP, Laumann EO, Levinson W, O'Muircheartaigh CA, Waite LJ. A study of sexuality among older adults in the United States. N Engl J Med. 2007;357(8):762-774.

3. Shifren JL, Monz BU, Russo PA, Segreti A, Johannes CB. Sexual problems and distress in United States women: prevalence and correlates. Obstet Gynecol. 2008;112(5):970-978.

4. American Psychiatric Association. Diagnostic and Statistical Manual of Mental Disorders. 4th ed. - Text Revision (DSM-IV-TR). Washington DC: American Psychiatric Association; 2000.

5. World Health Organization. International Statistical Classification of Diseases and Related Health Problems. 10th revision. Geneva: World Health Organization; 1992.

6. Basson R, Berman J, Burnett A, et al. Report on the International Consensus Development Conference on female sexual dysfunction: definition and classification. J Urol. 2000;163(3):888-893.

7. Basson R, Leiblum S, Brotto L, et al. Revised definitions of women's sexual dysfunction. $J$ Sex Med. 2004;1(1):24-39.

8. Basson R, Wierman M, van Lankveld J, Brotto L. Summary of the recommendations of sexual dysfunction in women. $J$ Sex Med. 2010;7 (1 Pt 2):314-326.

9. Brotto L, Bitzer J, Laan E, Leiblum S, Luria M. Women's sexual desire and arousal disorders. $J$ Sex Med. 2010;7(1 Pt 2):586-614.
10. Sand M, Fisher WA. Women's endorsement of models of female sexual response: the nurses' sexuality study. $J$ Sex Med. 2007;4(3): 708-719.

11. Brotto LA. The DSM diagnostic criteria for hypoactive sexual desire disorder in women. Arch Sex Behav. Epub 2009 Sep 24.

12. Dennerstein L, Koochaki P, Barton I, Graziottin A. Hypoactive sexual desire disorder in menopausal women: a survey of western European women. $J$ Sex Med. 2006;3(2):212-222.

13. Leiblum S, Koochaki P, Rodenberg C, Barton I, Rosen RC. Hypoactive sexual desire disorder in postmenopausal women: US results from the Women's International Study of Health and Sexuality (WISHeS). Menopause. 2006;13(1):46-56.

14. Hayes RD, Dennerstein L, Bennett CM, Koochaki PE, Leiblum SR, Graziottin A. Relationship between hypoactive sexual desire disorder and aging. Fertil Steril. 2007;87(1):107-112.

15. Hayes RD, Dennerstein L, Bennett CM, Sidat M, Gurrin LC, Fairley CK. Risk factors for female sexual dysfunction in the general population: exploring factors associated with low sexual function and sexual distress. J Sex Med. 2008;5(7):1681-1693.

16. Rosen RC, Shifren JL, Monz BU, Odom DM, Russo PA, Johannes CB. Correlates of sexually related personal distress in women with low sexual desire. J Sex Med. 2009;6(6):1549-1560.

17. Parish SJ, Clayton AH. Sexual medicine education: review and commentary. J Sex Med. 2007;4(2):259-267.

18. Brandenburg U, Bitzer J. The challenge of talking about sex: the importance of patient-physician interaction. Maturitas. 2009;63(2):124-127.

19. Althof SE, Dean J, Derogatis LR, Rosen RC, Sisson M. Current perspectives on the clinical assessment and diagnosis of female sexual dysfunction and clinical studies of potential therapies: a statement of concern. J Sex Med. 2005;2 Suppl 3:146-153.

20. Graziottin A, Serafini A, Palacios S. Aetiology, diagnostic algorithms and prognosis of female sexual dysfunction. Maturitas. 2009;63(2): $128-134$.

21. Bitzer J, Brandenburg U. Psychotherapeutic interventions for female sexual dysfunction. Maturitas. 2009;63(2):160-163.

22. Meston CM, Frohlich PF. The neurobiology of sexual function. Arch Gen Psychiatry. 2000;57(11):1012-1030.

23. Levine SB. The nature of sexual desire: a clinician's perspective. Arch Sexual Behav. 2003;32(3):279-285.

24. Nappi R, Salonia A, Traish AM, et al. Clinical biologic pathophysiologies of women's sexual dysfunction. $J$ Sex Med. 2005;2(1):4-25.

25. Pfaus JG. Pathways of sexual desire. J Sex Med. 2009;6(6):1506-1533.

26. Nappi RE. New attitudes to sexuality in the menopause: clinical evaluation and diagnosis. Climacteric. 2007;10 Suppl 2:105-108.

27. Shifren JL, Avis NE. Surgical menopause: effects on psychological well-being and sexuality. Menopause. 2007;14(3 Pt 2):586-591.

28. Nappi RE, Wawra K, Schmitt S. Hypoactive sexual desire disorder in postmenopausal women. Gynecol Endocrinol. 2006;22(6):318-323.

29. West SL, D'Aloisio AA, Agans RP, Kalsbeek WD, Borisov NN, Thorp JM. Prevalence of low sexual desire and hypoactive sexual desire disorder in a nationally representative sample of US women. Arch Intern Med. 2008;168(13):1441-1449.

30. Nappi RE, Lello S, Melis GB, Albani F, Polatti F, Genazzani AR. LEI (Lack of tEstosterone Impact) survey in a clinical sample with surgical menopause. Climacteric. 2009;12(6):533-540.

31. Davis SR, Burger H. Androgen and postmenopausal women. $J$ Clin Endocrinol Metab. 1996;81(8):2759-2763.

32. Rosen R, et al, editors. Androgen insufficiency in women: the Princeton Conference. Fertil Steril. 2002;77 Suppl 4:660-665.

33. Burger HG, Hale GE, Robertson DM, Dennerstein L. A review of hormonal changes during the menopausal transition: focus on findings from the Melbourne Women's Midlife Health Project. Hum Reprod Update. 2007;13(6):559-565.

34. Labrie F, Luu-The V, Labrie C, et al. Endocrine and intracrine sources of androgens in women: inhibition of breast cancer and other roles of androgens and their precursor dehydroepiandrosterone. Endocr Rev. $2003 ; 24(2): 152-182$. 
35. Davis SR, Davison SL, Donath S, Bell RJ. Circulating androgen levels and self-reported sexual function in women. JAMA. 2005;294(1): 91-96.

36. Salonia A, Pontillo M, Nappi RE, et al. Menstrual cycle-related changes in circulating androgens in healthy women with self-reported normal sexual function. J Sex Med. 2008;5(4):854-863.

37. Nappi RE, Lachowsky M. Menopause and sexuality: prevalence of symptoms and impact on quality of life. Maturitas. 2009;63(2): $138-141$.

38. Dennerstein L, Dudley EC, Hopper JL, Guthrie JR, Burger HG. A prospective population-based study of menopausal symptoms. Obstet Gynecol. 2000;96(3):351-358.

39. Dennerstein L, Dudley E, Burger H. Are changes in sexual functioning during midlife due to aging or menopause? Fertil Steril. 2001;76(3): 456-460.

40. Dennerstein L, Guthrie JR, Hayes RD, DeRogatis LR, Lehert P. Sexual function, dysfunction, and sexual distress in a prospective, population-based sample of mid-aged, Australian-born women. J Sex Med. 2008;5(10):2291-2299.

41. Dennerstein L, Lehert P, Burger $H$. The relative effects of hormones and relationship factors on sexual function of women through the natural menopausal transition. Fertil Steril. 2005;84(1):174-180.

42. Dennerstein L, Hayes R, Sand M, Lehert P. Attitudes toward and frequency of partner interactions among women reporting decreased sexual desire. J Sex Med. 2009;6(6):1668-1673.

43. Segraves R, Woodard T. Female hypoactive sexual desire disorder: history and current status. J Sex Med. 2006;3(3):408-418.

44. Al-Azzawi F, Bitzer J, Brandenburg U, et al. Therapeutic options for postmenopausal female sexual dysfunction. Climacteric. 2009;12(6);514-524.

45. Nappi RE, Polatti F. The use of estrogen therapy in women's sexual functioning. J Sex Med. 2009;6(3):603-616.

46. Panzer C, Guay A. Testosterone replacement therapy in naturally and surgically menopausal women. J Sex Med. 2009;68(1):8-18.

47. Davis SR, Nijland EA. Pharmacological therapy for female sexual dysfunction: has progress been made? Drugs. 2008;68(3): 259-264.

48. Wierman ME, Nappi RE, Avis N, et al. Endocrine aspects of women's sexual function. J Sex Med. 2010;7(1 Pt 2):561-585.

49. Alexander JL, Kotz K, Dennerstein L, Kutner SJ, Wallen K, Notelovitz M. The effects of postmenopausal hormone therapies on female sexual functioning: a review of double-blind, randomized controlled trials. Menopause. 2004;11(6 Pt 2):749-765.

50. Modelska K, Cummings S. Female sexual dysfunction in postmenopausal women: systematic review of placebo-controlled trials. Am J Obstet Gynecol. 2003;188(1):286-293.

51. Greenblatt RB, Barfield WE, Garner JF, Calk GL, Harrod JP Jr. Evaluation of an estrogen, androgen, estrogen-androgen combination, and a placebo in the treatment of the menopause. J Clin Endocrinol Metab. 1950;10(12):1547-1558.

52. Somboonporn W, Davis S, Seif MW, Bell R. Testosterone for periand postmenopausal women. Cochrane Database Syst Rev. 2005;Oct 19(4):CD004509.

53. Somboonporn W, Bell RJ. The benefits and risks of testosterone therapy for postmenopausal women taking HT. Cochrane Database Syst Rev. 2010. In press.

54. Braunstein GD. Safety of testosterone treatment in postmenopausal women. Fertil Steril. 2007;88(1):1-17.

55. Buster JE, Kingsberg SA, Aguirre O, et al. Testosterone patch for low sexual desire in surgically menopausal women: a randomized trial. Obstet Gynecol. 2005;105(5 Pt 1):944-952.

56. Simon J, Braunstein G, Nachtigall L, et al. Testosterone patch increases sexual activity and desire in surgically menopausal women with hypoactive sexual desire disorder. J Clin Endocrinol Metab. 2005;90(9):5226-5233.
57. Shifren JL, Braunstein GD, Simon JA, et al. Transdermal testosterone treatment in women with impaired sexual function after oophorectomy. N Engl J Med. 2000;343(10):682-688.

58. Kingsberg S, Shifren J, Wekselman K, Rodenberg C, Koochaki P, Derogatis L. Evaluation of the clinical relevance of benefits associated with transdermal testosterone treatment in postmenopausal women with hypoactive sexual desire disorder. J Sex Med. 2007;4(4 Pt1): 1001-1008.

59. Shifren JL, Davis SR, Moreau M, et al. Testosterone patch for the treatment of hypoactive sexual desire disorder in naturally menopausal women: results from the INTIMATE NM1 study. Menopause. 2006;13(5):770-779.

60. Davis SR, Moreau, M, Kroll R, et al. Testosterone for low libido in postmenopausal women not taking estrogen. $N$ Engl J Med. 2008;359(19):2005-2017.

61. Goldstat R, Briganti E, Tran J, Wolfe R, Davis SR. Transdermal testosterone therapy improves well-being, mood, and sexual function in premenopausal women. Menopause. 2003;10(5):390-398.

62. Snabes MC, Simes SM. Approved hormonal treatments for HSDD: an unmet medical need. J Sex Med. 2009;6(7):1846-1849.

63. Krapf JM, Simon JA. The role of testosterone in the management of hypoactive sexual desire disorder in postmenopausal women. Maturitas. 2009;63(3):213-219.

64. Schwenkhagen A, Studd J. Role of testosterone in the treatment of hypoactive sexual desire disorder. Maturitas. 2009;63(2): 152-159.

65. Braunstein GD. The Endocrine Society Clinical Practice Guideline and The North American Menopause Society position statement on androgen therapy in women: another one of Yogi's forks. J Clin Endocrinol Metab. 2007;92(11):4091-4093.

66. North American Menopause Society. The role of testosterone therapy in postmenopausal women: position statement of the North American Menopause Society. Menopause. 2005;12(5):496-511.

67. Wierman ME, Basson R, Davis SR, et al. Androgen therapy in women: an Endocrine Society Clinical Practice guideline. J Clin Endocrinol Metab. 2006;91(10):3697-3710.

68. Davis SR. The effects of tibolone on mood and libido. Menopause. 2002;9(3):162-170.

69. Nijland EA, Weijmar Schultz WC, Nathorst-Boös J, et al. Tibolone and transdermal E2/NETA for the treatment of female sexual dysfunction in naturally menopausal women: results of a randomized active-controlled trial. J Sex Med. 2008;5(3):646-656.

70. Labrie F, Luu-The V, Labrie C, et al. Endocrine and intracrine sources of androgens in women: inhibition of breast cancer and other roles of androgens and their precursor dehydroepiandrosterone. Endocr Rev. 2003;24(2):152-182.

71. Rowland DL, Tai W. A review of plant-derived and herbal approaches to the treatment of sexual dysfunctions. J Sex Marital Ther. 2003;29(3):185-205.

72. Taylor MJ. Strategies for managing antidepressant-induced sexual dysfunction: a review. Curr Psychiatry Rep. 2006;8(6): 431-436.

73. Meston CM, Rellini AH, Telch MJ. Short- and long-term effects of Ginkgo biloba extract on sexual dysfunction in women. Arch Sex Behav. 2008;37(4):530-547.

74. Althof SE. What's new in sex therapy. J Sex Med. 2010;7(1):5-13.

75. McCabe MP. Evaluation of a cognitive behavior therapy program for people with sexual dysfunction. J Sex Marital Ther. 2001;27(3):259-271.

76. Trudel G, Marchand A, Ravart M, Aubin S, Turgeon L, Fortier P. The effect of a cognitive behavioral group treatment program on hypoactive sexual desire in women. Sex Rel Ther. 2001;16(1):145-64.

77. McCabe M, Althof SE, Assalian P, et al. Psychological and interpersonal dimensions of sexual function and dysfunction. $J$ Sex Med. 2010;7(1):327-336. 
78. Clayton AH, Dennerstein L, Fisher WA, Kingsberg SA, Perelman MA, Pyke RE. Standards for clinical trials in sexual dysfunction in women: research designs and outcomes assessment. J Sex Med. 2010;7(1):541-560.

79. Segraves RT, Clayton A, Croft H, Wolf A, Warnock J. Bupropion sustained release for the treatment of hypoactive sexual desire disorder in premenopausal women. J Clin Psychopharmacol. 2004;24(3):339-342.
80. Caruso S, Agnello C, Intelisano G, Farina M, Di Mari L, Cianci A Placebo-controlled study on efficacy and safety of daily $\backslash$ apomorphine SL intake in premenopausal women affected by hypoactive sexual desire disorder and sexual arousal disorder. Urology. 2004;63(5): 955-959.

81. Borsini F, Evans K, Jason K, Rohde F, Alexander B, Pollentier S. Pharmacology of flibanserin. CNS Drug Rev. 2002;8(2):117-142.

\section{Publish your work in this journal}

The International Journal of Women's Health is an international, peerreviewed open-access journal publishing original research, reports, reviews and commentaries on all aspects of women's healthcare including gynecology, obstetrics, and breast cancer. Subject areas include: Chronic conditions (migraine headaches, arthritis, osteoporosis);
Endocrine and autoimmune syndromes; Sexual and reproductive health; Psychological and psychosocial conditions. The manuscript management system is completely online and includes a very quick and fair peer-review system. Visit http://www.dovepress.com/ testimonials.php to read real quotes from published authors.

Submit your manuscript here: http://www.dovepress.com/international-journal-of-womens-health-journal 